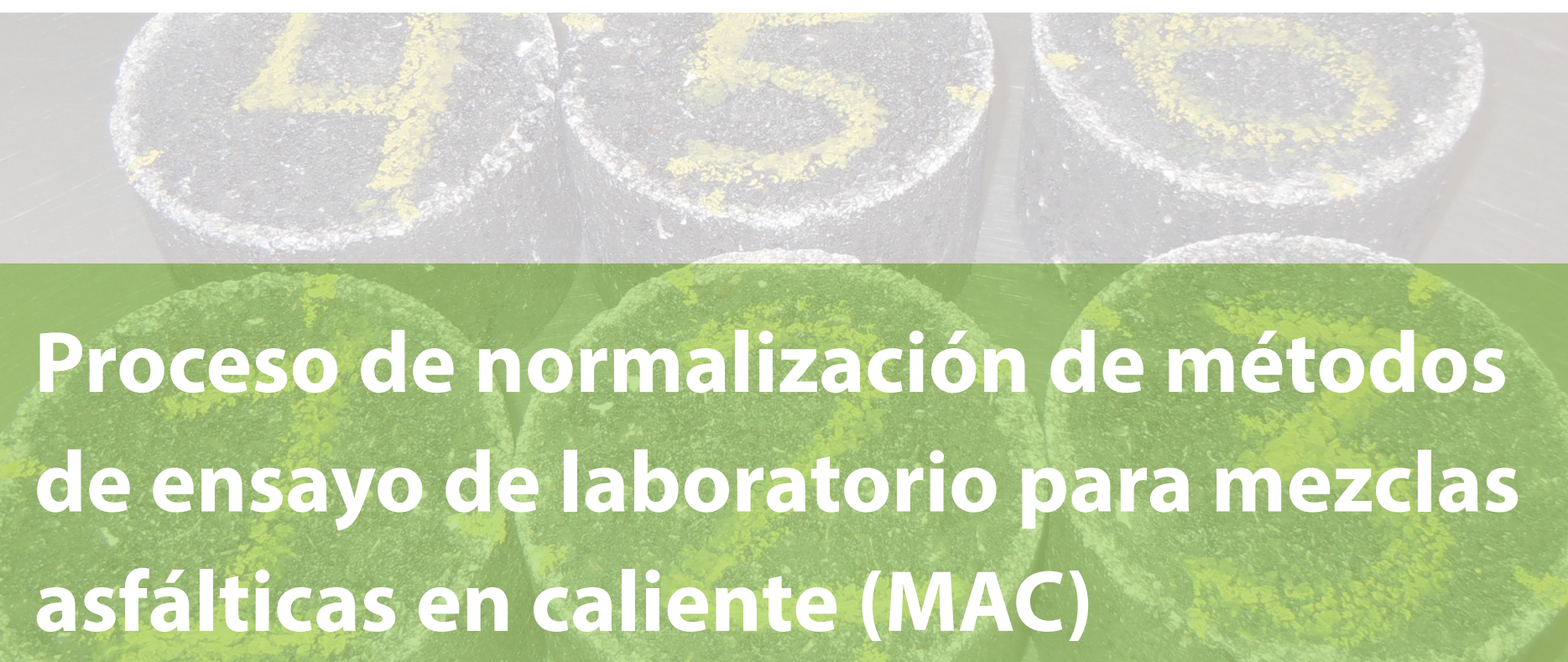

STANDARDIZATION PROCESS OF LABORATORY TEST METHODS FOR HOT MIX ASPHALT (HMA)

\section{Ing. Mónica Jiménez Acuña}

Jefe de Laboratorio de Ensayos Dinámicos para Pavimentos

LanammeUCR, Costa Rica

monica.jimenez@ucr.ac.cr

\section{Mariana Montero Vega}

Estudiante de Ingeniería Civil

Universidad de Costa Rica, Costa Rica

mariana.montero.v@gmail.com
Índices y Bases de Datos:

\section{latindex ucrindex}

revistas.ucr.ac.cr/index.php/materiales

(c) lanamme.ucr.ac.cr

@ metodosymateriales.lanamme@ucr.ac.cr
Políticas de Uso:

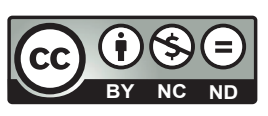

Revista Métodos y Materiales por LanammeUCR se distribuye bajo: Licencia Creative Commons Atribución-NoComercial-SinDerivar 4.0 Internacional. ISSN impreso: 2215-342X. ISSN electrónico: 2215-4558 


\section{Proceso de normalización de métodos de ensayo de laboratorio para mezclas asfálticas en caliente (MAC)}

\section{STANDARDIZATION PROCESS OF LABORATORY TEST METHODS FOR HOT MIX ASPHALT (HMA)}

Ing. Mónica Jiménez Acuña

Jefe de Laboratorio de Ensayos Dinámicos para Pavimentos LanammeUCR, Costa Rica

monica.jimenez@ucr.ac.cr

\author{
Mariana Montero Vega \\ Estudiante de Ingeniería Civil \\ Universidad de Costa Rica, Costa Rica \\ mariana.montero.v@gmail.com
}

Fecha de recepción: 8 de setiembre de 2016 / Fecha de aprobación: 2 de junio de 2017

\section{RESUMEN}

El Instituto de Normas Técnicas de Costa Rica (INTECO) nace en 1987 como respuesta a una necesidad costarricense de normalización técnica. INTECO ha evolucionado enormemente a través de los años elaborando una gama muy extensa de normativas con alrededor de 30 comités técnicos y más de 500 normas publicadas. Dentro de estos comités se encuentra la "CTN 04 Mezclas Bituminosas y Ligantes Asfalticos" perteneciente a la categoría de Mezclas Asfálticas la cual nace en el 2004 gracias a la solicitud del LanammeUCR.

Este documento incluye un resumen de cada norma INTECO relacionada a Mezclas Bituminosas, con imágenes ilustrativas del equipo y recomendaciones de profesionales del LanammeUCR para la buena práctica de dichos procesos. A su vez, incluye tres tablas comparativas en donde se demuestran las diferencias más relevantes del equipo, procedimiento y criterios de aceptación entre las normas más actualizadas de AASHTO y ASTM de mezclas bituminosas con las equivalentes a las INTECO.

Estos métodos tienen más de 7 años de no ser actualizados en Costa Rica, por lo que se invita a los anteriores miembros del comité técnico y a cualquier persona en el medio interesada a conformar un nuevo equipo de trabajo para lograr no solo actualizar dichas normas sino que también crear nuevas.

PALABRAS CLAVE: Normalización, ensayo, ensayo de laboratorio, mezcla asfáltica en caliente.

\section{ABSTRACT}

The Technical Standards Institute of Costa Rica (INTECO) was created in 1987 in response to a Costa Rican need for technical standardization. INTECO has greatly evolved over the years developing a very wide range of regulations with around 30 technical committees and more than 500 published standards. Within these committees is the "CTN 04 bituminous mixtures and asphalts binders" which belongs to the category of Asphalt Mixtures, developed in 2004 thanks to the efforts of LanammeUCR.

This document includes a summary of each INTECO standard related to asphalt mixes, with illustrative images of equipment and professional LanammeUCR recommendations to ensure the correct application of these processes. This summary also includes three comparative tables with the most important differences present in: equipment, procedures and precision and bias between the latest AASHTO and ASTM bituminous mixtures standards and their equivalent to INTECO standard.

These methods have not being updated in Costa Rica in more than seven years, so the former members of the technical committee as well as anyone in the field are invited to be part of a new team to not only update these rules but also create new ones.

KEYWORDS: Standardization, tests, laboratory testing, hot mix asphalt. 


\section{INTRODUCCIÓN}

El Instituto de Normas Técnicas de Costa Rica (INTECO) nace en 1987 como respuesta a una necesidad costarricense de normalización técnica. No es hasta el 21 de mayo del 2002 que fue reconocida por la ley $\mathrm{N}^{\circ} 8279$ como un Ente Nacional de Normalización, el cual corresponde a una entidad privada sin fines de lucro. Dentro de sus labores se encuentra liderar la creación de normas costarricenses que impulsen el desarrollo socio-económico del país apegándose a las buenas prácticas de normalización internacionalmente aceptadas. Actualmente INTECO cuenta con 50 empleados los cuales se dividen en un Consejo Directivo y colaboradores. Dentro de los colaboradores existen directores ejecutivos, asistentes, auditores, coordinadores, directores, gestores entre otros.

INTECO ha evolucionado enormemente a través de los años elaborando una gama muy extensa de normativas con alrededor de 30 comités técnicos y más de 500 normas publicadas. Dicha institución cuenta además con una plataforma virtual en donde pueden ser consultadas cualquiera de estas normas a muy bajos costos desde cualquier punto del país (http://www.inteco.or.cr). Esta facilidad tecnológica permite el acceso a mucha información tanto académica como científica de lo cual se benefician miles de costarricenses.

Dentro de estos comités se encuentra la "CTN 04 Mezclas Bituminosas y Ligantes Asfalticos" perteneciente a la categoría de Mezclas Asfálticas la cual nace en el 2004 gracias a la solicitud del LanammeUCR de crear una serie de normativas que sirvieran de guía en el desarrollo de métodos de ensayo en relación con las mezclas asfálticas, sus propiedades y su manipulación. Es por esta razón que se desarrollan trece normas alrededor de este tema a cargo del Normalizador del Comité Jaime Restrepo. Dentro de los tópicos de estas normas se tratan temas como estabilidad y flujo Marshall, determinación del contenido de asfalto, extracción cuantitativa de asfalto, determinación del efecto del agua en la resistencia a la compresión de mezclas asfálticas, determinación del porcentaje de vacíos, entre muchos otros que se mencionarán más adelante. Lamentablemente la creación de estas normativas se detuvo en el 2009 y desde entonces no ha habido ningún tipo de actualización de las normas anteriores ni tampoco creación de nuevas normas que respalden la utilización de nuevas tecnologías en pavimentos.

\section{RESUMEN DE LOS MÉTODOS}

\subsection{Métodos de ensayo/prueba para la determi- nación de la gravedad especifica bruta de mezclas asfálticas compactadas, utilizando el método de superficie saturada seca (INTE-04-01-01-04)}

Este método de ensayo tiene como objetivo determinar la gravedad especifica bruta de especímenes de ensayo compactados de mezclas bituminosas, utilizando el método de superficie saturada seca. Se ensayan mínimo 3 especímenes por muestra. Es importante rescatar que dicho ensayo no se debe de aplicar a muestras que absorban $2 \%$ de su volumen de agua. El equipo más relevante para esta prueba es: la balanza, accesorio de suspensión, recipiente aforado y un baño de agua.

Método A: Para realizar este ensayo se debe secar el espécimen de ensayo y registrar su peso seco (A), luego sumergir dicho espécimen durante 4 minutos y registrar el peso sumergido (C) finalmente secarlo rápidamente con una toalla húmeda y determinar el peso en condición saturado superficie seca (B). Para calcular la gravedad específica bruta se realiza la siguiente operación:

$$
\mathrm{G}_{\mathrm{mb}}=\frac{\mathrm{A}}{\mathrm{B}-\mathrm{C}}
$$

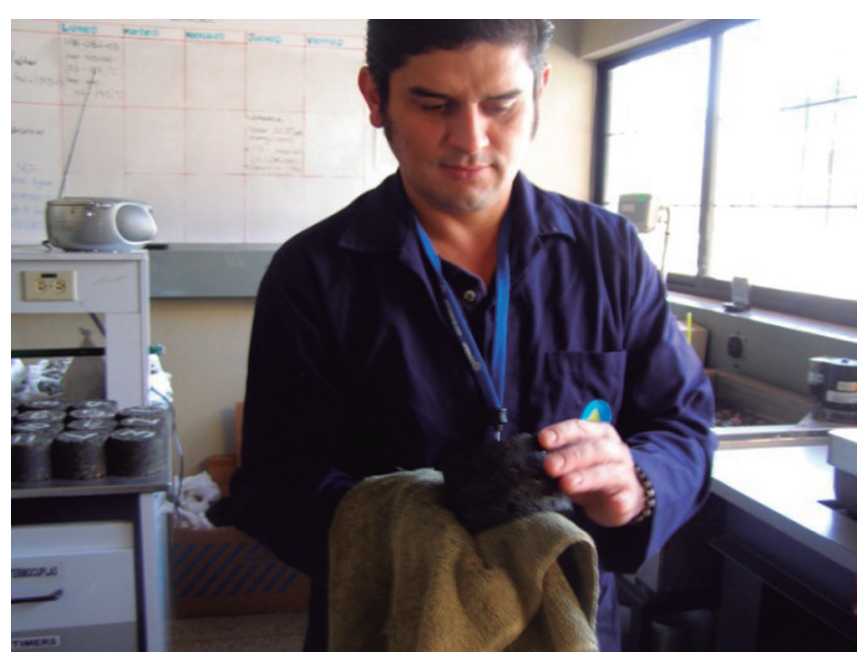

Figura 1. Llevando Espécimen a Condición de Superficie Saturada Seca. Fuente: LanammeUCR, 2016. 
Método B: La principal diferencia que presenta con el primer método es que en este el espécimen se debe de sumergir en el baño de agua durante 10 minutos y luego de secarlo sumergirlo en un recipiente aforado con agua potable, se tapa y se deja estabilizar por 60 segundos para posteriormente pesarlo (E); siendo D el peso del recipiente aforado lleno con agua tenemos que:

$$
G_{m b}=\frac{A}{B+D-E}
$$

Método C: Este es utilizado para establecer si un espécimen no tiene que ser reutilizado en el ensayo dado su nivel de humedad. Se procede a secar el espécimen en el horno a una temperatura de $110{ }^{\circ} \mathrm{C}$ y una vez frío se determina su peso seco como A y proseguir con los pesos sumergido y superficie saturado seco. Cabe mencionar que es posible realizar correcciones de la gravedad específica bruta por temperatura del agua utilizando un factor de corrección "K" para cada una de las temperaturas y utilizando la siguiente ecuación:

$$
G b s_{25^{\circ} \mathrm{C}}=K \times G b s_{\text {otratemperatura }}
$$

Los factores de corrección se encuentran en el Anexo A de la norma INTE-04-01-01-04

Los criterios de aceptación de la prueba se despliegan en la Tabla 1:

\begin{tabular}{|c|c|c|}
\hline \multicolumn{2}{|c|}{ Tabla 1. Criterios de aceptación INTE-04-01-01-04 } \\
\hline $\begin{array}{c}\text { Índice de ensayo } \\
\text { y tipo }\end{array}$ & $\begin{array}{c}\text { Desviación } \\
\text { estándar }\end{array}$ & $\begin{array}{c}\text { Rango aceptable de } \\
\text { dos resultados }\end{array}$ \\
\hline $\begin{array}{c}\text { Precisión de un } \\
\text { operador }\end{array}$ & 0,0124 & 0,035 \\
\hline $\begin{array}{c}\text { Precisión } \\
\text { multilaboratorio }\end{array}$ & 0,0269 & 0,076 \\
\hline
\end{tabular}

\subsection{Métodos de ensayo/prueba para la determi- nación de la gravedad especifica bruta de mezclas asfálticas compactadas, utilizando especímenes de ensayo/prueba cubiertos con parafina (INTE- 04-01-02-04)}

Este método de ensayo tiene como objetivo determinar la gravedad específica bruta de especímenes de ensayo compactados de mezclas bituminosas, utilizando especímenes de ensayo/prueba cubiertos con parafina. Se ensayan mínimo 3 especímenes por muestra. Los equipos más relevantes para esta prueba son: el dispositivo de pesaje, accesorio de suspensión, un termómetro, recipiente aforado y un baño de agua. Dispositivo de calentamiento para derretir la parafina.

Método A: Para realizar este ensayo se debe secar el espécimen de ensayo y registrar su peso seco (A), luego recubrir toda la superficie con parafina derretida suficientemente gruesa para sellar todos los vacios dejar enfriar durante 30 minutos y pesar (D). Seguidamente se pesa el espécimen de ensayo en un baño de agua (E) y finalmente se designa la gravedad especifica de la parafina como $\mathrm{F}$.

$$
G_{m b}=\frac{A}{D-E-\left(\frac{D-A}{F}\right)}
$$

Método B: Lo que se diferencia del método A es que luego de calcular el peso del espécimen recubierto de parafina se debe de llenar el recipiente aforado y colocar el espécimen y taparlo para posteriormente pesarlo. Con E siendo el peso del recipiente y el espécimen, $\mathrm{D}$ el peso del recipiente y $\mathrm{C}$ el peso del espécimen recubierto de parafina tenemos:

$$
G_{m b}=\frac{A}{D-\left[E-C+\left(\frac{D-A}{F}\right)\right]}
$$

Los criterios de aceptación de la prueba se basan en que para una prueba realizada por duplicado, por el mismo operador no deben de ser consideradas sospechosas a menos que difieran en más de 0,02.

\subsection{Métodos de ensayo/prueba para la determi- nación de la gravedad especifica máxima teórica y la densidad de mezclas asfálticas para pavimentos (INTE 04-01-03-05)}

Este método de ensayo tiene como objetivo determinar la gravedad específica máxima teórica y la densidad de mezcla asfáltica sin compactar para pavimentos a $25^{\circ} \mathrm{C}$. Se ensayan mínimo 2 especímenes por muestra. Los equipos más relevantes para esta prueba son: contenedores para vacío, agitador mecánico, balanza, bomba de vacío, manómetro de presión residual, manómetro o medidor de vacío, termómetro, baño de agua. 
Método A: Una muestra de mezcla asfáltica "desmenuzada" y secada al horno se pesa, luego se debe de colocar en el contenedor de vacío y llenarla con agua completamente. Seguidamente se remueve el aire atrapado hasta una presión de $(3,7 \pm 0,3) \mathrm{kPa}$ y mantenerlo durante $(15 \pm 2)$ min y agitar vigorosamente, finalizados los 15 minutos se libera presión de vacío lentamente. Para finalizar se escogen entre 2 tipos de pesado: pesado sumergido y pesado al aire. Para el primer caso se suspende el contenedor en un baño de agua y se determina su peso $(\mathrm{C})$ después de 10 minutos; en el segundo caso se llena con agua el frasco completamente asegurándose que no queden burbujas de aire y se determina el peso del contenedor completamente lleno (E).

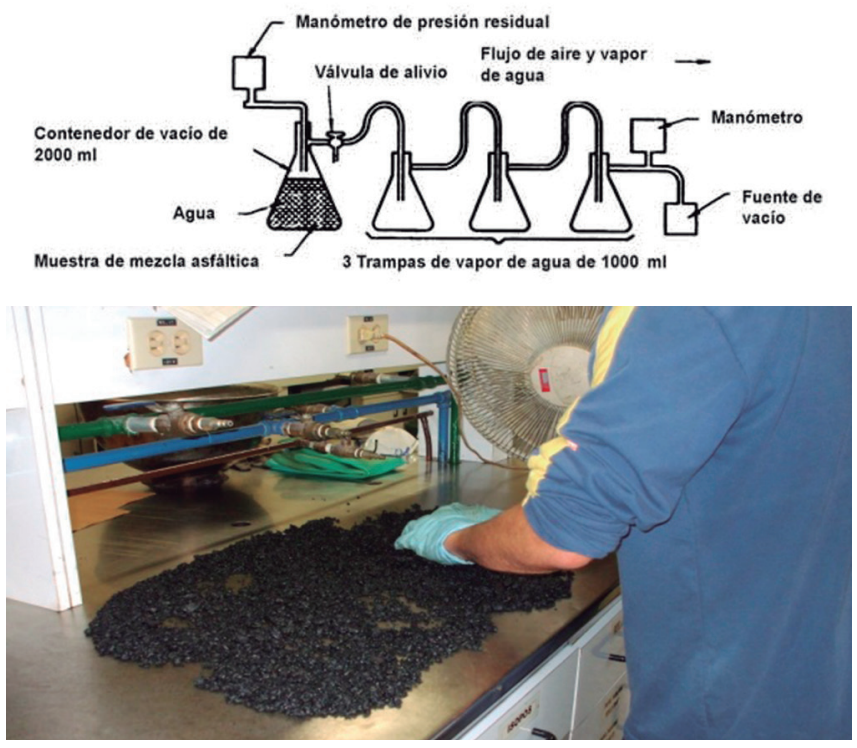

Figura 2. Arreglo del equipo de ensayo y extensión de mezcla de la prueba. Fuente: INTECO, 2005.

Pesado sumergido:

$$
G_{m t}=\frac{A}{A-(C-B)}
$$

Pesado al aire:

$$
\mathrm{G}_{\mathrm{mt}}=\frac{\mathrm{A}}{\mathrm{A}+\mathrm{D}+\mathrm{E}}
$$

Método B: Si los poros de los agregados no están totalmente sellados por una capa de material asfaltico, que es muy probable en agregados con absorción de más del $2 \%$ de agua, se debe decantar el agua a través de una malla $\mathrm{N}^{\circ} 200(0,075$ $\mathrm{mm}$ ) para evitar la pérdida de material fino. Se extiende la muestra sobre una superficie absorbente y se seca al aire hasta llevarla a masa constante, se puede utilizar con un ventilador.

\begin{tabular}{|c|c|c|c|}
\hline \multicolumn{4}{|c|}{ Tabla 2. Criterios de aceptación INTE-04-01-03-05 } \\
\hline & $\begin{array}{c}\text { Índice de ensayo } \\
\text { y tipo }\end{array}$ & $\begin{array}{c}\text { Desviación } \\
\text { estándar }\end{array}$ & $\begin{array}{l}\text { Rango aceptable } \\
\text { de dos resultados }\end{array}$ \\
\hline \multirow{2}{*}{$\begin{array}{c}\text { Método } \\
\text { A }\end{array}$} & $\begin{array}{l}\text { Precisión de un } \\
\text { operador }\end{array}$ & 0,0040 & 0,011 \\
\hline & $\begin{array}{c}\text { Precisión } \\
\text { multilaboratorio }\end{array}$ & 0,0064 & 0,019 \\
\hline \multirow{2}{*}{$\begin{array}{c}\text { Método } \\
\text { A }\end{array}$} & $\begin{array}{l}\text { Precisión de un } \\
\text { operador }\end{array}$ & 0,0064 & 0,018 \\
\hline & $\begin{array}{c}\text { Precisión } \\
\text { multilaboratorio }\end{array}$ & 0,0193 & 0,055 \\
\hline
\end{tabular}

Los criterios de aceptación de la prueba son los siguientes:

\subsection{Métodos de ensayo/prueba para determinar el porcentaje de vacíos de aire de mezcla asfálticas den- sas y abiertas para pavimentos (INTE 04-01-04-05)}

Este método de ensayo tiene como objetivo determinar el porcentaje de vacíos de aire en mezclas asfálticas densas y abiertas para pavimentos. Este se debe calcular a partir de la medición de su peso seco y su volumen. Una vez calculado el volumen por el método de alturas y diámetros se calcula la densidad y se divide entre $0,99707 \mathrm{~g} / \mathrm{cm} 3$ para obtener la gravedad específica bruta. La gravedad específica máxima se calcula mediante la norma INTE 04-01-03-04 tomando la misma muestra. El porcentaje de vacíos de calcula de la siguiente forma:

$$
\% V=100 *\left(1-\frac{G_{m b}}{G_{m t}}\right)
$$

Los criterios de aceptación de la prueba son los siguientes:

\begin{tabular}{|c|c|c|c|}
\hline \multicolumn{3}{|c|}{ Tabla 3. Criterios de aceptación INTE-04-01-04-05 } \\
\hline \multirow{2}{*}{$\begin{array}{c}\text { Índice de ensayo } \\
\text { y tipo }\end{array}$} & $\begin{array}{c}\text { Desviación } \\
\text { estándar }\end{array}$ & $\begin{array}{c}\text { Rango aceptable } \\
\text { de dos resultados }\end{array}$ \\
\hline \multirow{2}{*}{$\begin{array}{c}\text { Superficie } \\
\text { saturada } \\
\text { seca }\end{array}$} & $\begin{array}{c}\text { Precisión de un } \\
\text { operador }\end{array}$ & 0,32 & 0,91 \\
\cline { 2 - 4 } & $\begin{array}{c}\text { Precisión } \\
\text { multilaboratorio }\end{array}$ & - & - \\
\hline
\end{tabular}




\begin{tabular}{|c|c|c|c|}
\hline \multicolumn{3}{|c|}{ Tabla 3. Criterios de aceptación INTE-04-01-04-05 } \\
\hline \multirow{2}{*}{$\begin{array}{c}\text { Índice de ensayo } \\
\text { y tipo }\end{array}$} & $\begin{array}{c}\text { Desviación } \\
\text { estándar }\end{array}$ & $\begin{array}{c}\text { Rango aceptable } \\
\text { de dos resultados }\end{array}$ \\
\hline \multirow{2}{*}{$\begin{array}{c}\text { Recubiertos } \\
\text { con } \\
\text { parafina }\end{array}$} & $\begin{array}{c}\text { Precisión de un } \\
\text { operador }\end{array}$ & 0,51 & 1,44 \\
\cline { 2 - 4 } & $\begin{array}{c}\text { Precisión } \\
\text { multilaboratorio }\end{array}$ & 1,09 & 3,08 \\
\hline
\end{tabular}

\subsection{Métodos de ensayo/prueba para determinar la resistencia al daño inducido por la humedad en mezclas asfálticas compactadas (INTE 04-01-05-05)}

Este método de ensayo tiene como objetivo la medición del cambio en la resistencia a la tensión diametral para mezclas asfálticas compactadas, como resultado de los efectos de la saturación de agua y un acondicionamiento acelerado en un baño de agua a $60{ }^{\circ} \mathrm{C}$. Los equipos más relevantes para esta prueba son: contenedores para vacío, una balanza, baño de agua, bolsa de plástico impermeable, horno, marco, celda y muelas de carga.

Se debe de hacer al menos 6 especímenes para cada prueba, la mitad debe de ser ensayados en condición seca y la otra debe de ser ensayada en condición de saturación parcial y condicionamiento húmedo. La mezcla debe de ser compactada a $(7,0 \pm 0,5) \%$ de vacíos de aire. Para realizar este ensayo se debe separar cada grupo de especímenes de ensayo en dos subgrupos de igual número de especímenes de ensayo. El primer subgrupo debe alcanzar la temperatura de prueba $(25 \pm 1)^{\circ} \mathrm{C}$ por no menos de $2 \mathrm{~h}$. Para el subgrupo 2 se debe sumergir los especímenes de ensayo en agua, y se debe de aplicar vacío entre 13-67 kPa de presión absoluta, seguidamente quitar la presión y dejar el espécimen sumergido por un corto tiempo (S2).

Seguidamente se colocan cada grupo de especímenes y se aplica carga al espécimen a razón constante de aproximadamente 50 $\mathrm{mm}$ por minuto. Se debe cargar hasta que aparezca una grieta vertical. Siendo P la carga promedio máxima y D el diámetro del espécimen, la resistencia a la tensión se calcula de la siguiente forma:

$$
S_{t}=\frac{2000 P}{\Pi t D}
$$
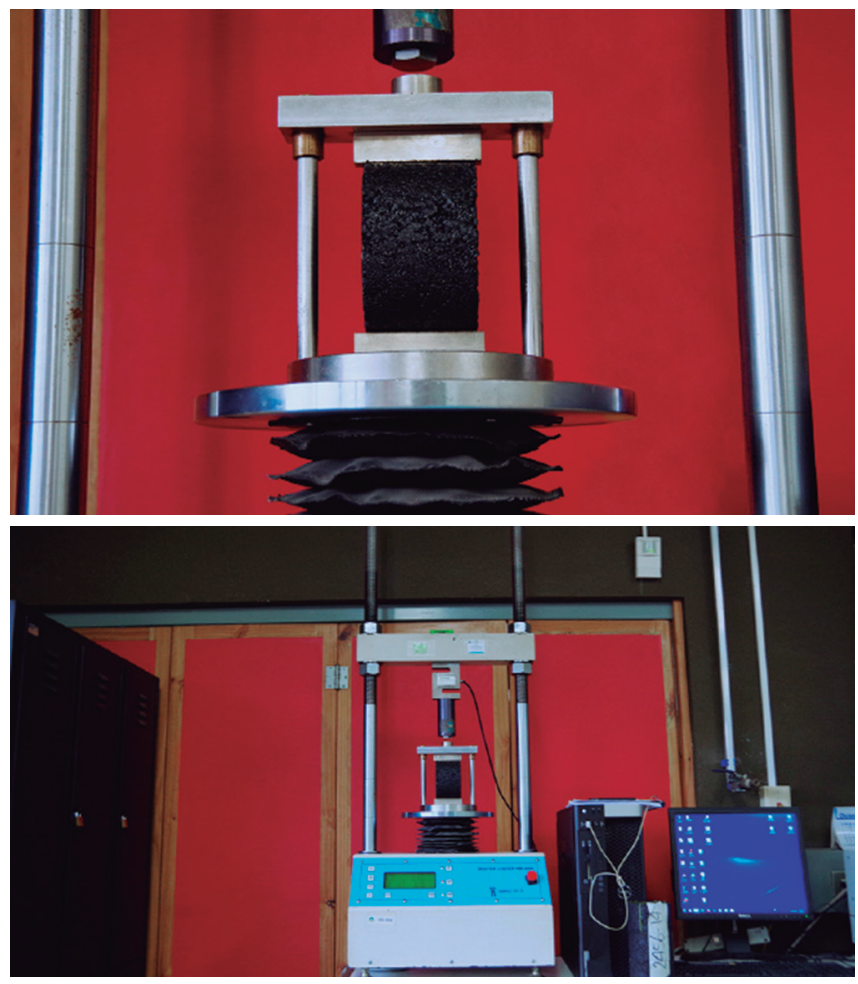

Figura 3. Falla a Tensión Diametral. Fuente: LanammeUCR, 2016.

\subsection{Métodos de ensayo/prueba para determinar la resistencia a la compresión de mezclas asfálti- cas. (INTE 04-01-06-05)}

Este método de ensayo tiene como objetivo la medición de la resistencia a la compresión de mezclas asfálticas compactadas. El equipo más relevante para esta prueba es: moldes y émbolos, soportes, maquina de falla, horno, baño de agua, balanza, máquina de mezclado y espátulas. Se ensayan mínimo 3 especímenes por muestra.

Se determina la gravedad específica bruta de cada espécimen de acuerdo al procedimiento descrito en INTE 04-01-01-04. Seguidamente se deben llevar los especímenes de ensayo a la temperatura de ensayo $(25 \pm 1){ }^{\circ} \mathrm{C}$ por lo menos durante $4 \mathrm{~h}$. Finalmente se deben ensayar los especímenes de ensayo en compresión axial sin soportes laterales a una velocidad uniforme de deformación vertical de $0,05 \mathrm{~mm} / \mathrm{min} \cdot \mathrm{mm}$ de la altura. Para especímenes de ensayo de 101,6 mm de altura, utilizar una velocidad de 50,8 $\mathrm{mm} / \mathrm{min}$.

Los criterios de aceptación de la prueba son los siguientes: 


\begin{tabular}{|c|c|c|}
\hline \multicolumn{2}{|c|}{ Tabla 4. Criterios de aceptación INTE-04-01-06-05 } \\
\hline $\begin{array}{c}\text { Índice de ensayo } \\
\text { y tipo }\end{array}$ & $\begin{array}{c}\text { Desviación } \\
\text { estándar (kPa) }\end{array}$ & $\begin{array}{c}\text { Rango aceptable de } \\
\text { dos resultados (kPa) }\end{array}$ \\
\hline $\begin{array}{c}\text { Precisión de un } \\
\text { operador }\end{array}$ & 145 & 407 \\
\hline $\begin{array}{c}\text { Precisión } \\
\text { multilaboratorio }\end{array}$ & 372 & 1055 \\
\hline
\end{tabular}

\subsection{Métodos de ensayo/prueba para determinar el efecto del agua en la resistencia a la compresión de mezclas asfálticas compactadas (INTE 04-01-07-05)}

Este método de ensayo tiene como objetivo la medición de la resistencia a la compresión como resultado del daño por la acción del agua en mezclas asfálticas compactadas. El equipo más relevante para esta prueba es: baños de agua, dispositivos de pesaje y platos planos.

Se deben preparar al menos 6 especímenes de ensayo cilíndricos de $(101,6 \pm 2,56) \mathrm{mm}$ de altura para cada ensayo. Para realizar este ensayo se debe separar cada grupo de especímenes de ensayo en dos subgrupos de igual número de especímenes de ensayo. El primer subgrupo debe alcanzar la temperatura de prueba $(25 \pm 1){ }^{\circ} \mathrm{C}$ por no menos de $4 \mathrm{~h}$ y determinar su resistencia a la compresión según el ensayo INTE 04-01-06-04 (S1). Para el subgrupo 2 se debe sumergir los especímenes de ensayo en agua durante $(24 \pm 1) \mathrm{h}$ a $(60$ $\pm-1)^{\circ} \mathrm{C}$, posteriormente se deben de trasladar a un segundo baño de agua manteniendo $(25 \pm 1){ }^{\circ} \mathrm{C}$ durante $(2,00 \pm 0,17) \mathrm{h}$ para finalmente determinar la resistencia a compresión de la misma manera que con el subgrupo $1\left(\mathrm{~S}_{2}\right)$.

Indice de resistencia retenida, $\%=\frac{\mathrm{S}_{2}}{\mathrm{~S}_{1}} * 100$

Los criterios de aceptación de la prueba son los siguientes:

\begin{tabular}{|c|c|c|}
\hline \multicolumn{3}{|c|}{ Tabla 5. Criterios de aceptación INTE-04-01-07-05 } \\
\hline $\begin{array}{c}\text { Índice de ensayo } \\
\text { y tipo }\end{array}$ & $\begin{array}{c}\text { Desviación } \\
\text { estándar (\%) }\end{array}$ & $\begin{array}{c}\text { Rango aceptable de } \\
\text { dos resultados (\%) }\end{array}$ \\
\hline $\begin{array}{c}\text { Precisión de un } \\
\text { operador }\end{array}$ & 6 & 18 \\
\hline
\end{tabular}

Tabla 5. Criterios de aceptación INTE-04-01-07-05

\begin{tabular}{|c|c|c|}
$\begin{array}{c}\text { Índice de ensayo } \\
\text { y tipo }\end{array}$ & $\begin{array}{c}\text { Desviación } \\
\text { estándar (\%) }\end{array}$ & $\begin{array}{c}\text { Rango aceptable de } \\
\text { dos resultados (\%) }\end{array}$ \\
\hline $\begin{array}{c}\text { Precisión } \\
\text { multilaboratorio }\end{array}$ & 18 & 50 \\
\hline
\end{tabular}

\subsection{Métodos de ensayo para extracción cuantitativa de asfalto de mezclas asfálticas (INTE 04-01-08-05)}

Este método de ensayo tiene como objetivo determinar el contenido de asfalto en mezclas asfálticas y especímenes de ensayo de pavimentos utilizando la máquina de centrífuga. El equipo más relevante para esta prueba es: horno, bandeja, balanzas, plantilla eléctrica, recipiente graduado, recipiente, crisol de porcelana, desecador y balanza semi analítica. Se analizan mínimo 2 especímenes por muestra.

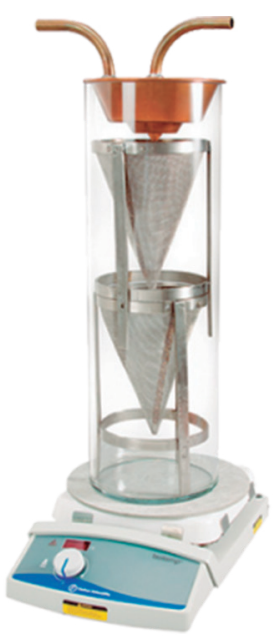

Figura 4. Extractor por Reflujo para el Método B. Fuente: Humboldt, 2016.

Método A (Centrífuga): Para realizar este ensayo se debe de determinar el contenido de agua $\left(\mathrm{M}_{2}\right)$, registrar la masa del espécimen $\left(\mathrm{M}_{1}\right)$ y colocarlo dentro del tazón cubriéndolo de disolvente tricloroetileno (más utilizado en el LanammeUCR) y dejarlo reposar por no más de 1 hora. Seguidamente trasladar el tazón al equipo de extracción, ajustar el filtro al borde del tazón y colocar un recipiente apropiado en el drenaje para recolectar el extracto. Se debe de iniciar el centrifugado lentamente, incrementando gradualmente la velocidad hasta un máximo de 3600 revoluciones por minuto o hasta que el 
disolvente cese de drenar. Una vez que la máquina se detenga, agregar $200 \mathrm{ml}$ de disolvente y repetir el procedimiento hasta que el extracto no sea tan oscuro o salga de un color claro. Remover el filtro circular del tazón y secar en un horno al igual que todo el contenido del tazón a masa constante a una temperatura $(110 \pm 5){ }^{\circ} \mathrm{C}$. La suma del agregado en la bandeja más el incremento en la masa de los filtros circular se le llama $\mathrm{M}_{3}$. Por último se anota el volumen del extracto total de la probeta $\left(\mathrm{V}_{1}\right)$, se agita fuertemente e inmediatamente se extrae una submuestra de $100 \mathrm{ml}\left(\mathrm{V}_{2}\right)$ y se deja evaporar hasta secar en un baño de vapor o en una plantilla eléctrica. Se incinera el residuo de ceniza y después de 1 hora se seca en un horno a $(110 \pm 5)^{\circ} \mathrm{C}$ hasta masa constante y se determina la masa (G).

$$
M_{4}=\frac{V_{1}}{V_{2}} * G
$$

Porcentaje de Asfalto $=\left[\frac{\left(M_{1}-M_{2}\right)-\left(M_{3}+M_{4}\right)}{M_{1}-M_{2}}\right] * 100$

Método B (Reflujo): La diferencia más relevante que existe con este método y el anterior es que se utilizan recipientes cónicos de metal en los cuales se pone la muestra y el disolvente. Estos se colocan sobre un aislador térmico; en un condensador se hace pasar un flujo continuo de agua fría. Se ajusta la temperatura del calentador eléctrico hasta que el disolvente hierva lentamente y fluya una corriente continua de disolvente condensado dentro del cono hasta que el mismo fluya de un color claro. Remover el ensamble de los marcos del cilindro y secar a masa constante.

Los criterios de aceptación de la prueba son los siguientes:

\begin{tabular}{|c|c|c|}
\hline \multicolumn{2}{|c|}{ Tabla 6. Criterios de aceptación INT E-04-01-08-05 } \\
\hline $\begin{array}{c}\text { Índice de ensayo } \\
\text { y tipo }\end{array}$ & $\begin{array}{c}\text { Desviación } \\
\text { estándar (\%) }\end{array}$ & $\begin{array}{c}\text { Rango aceptable de } \\
\text { dos resultados (\%) }\end{array}$ \\
\hline $\begin{array}{c}\text { Precisión de un } \\
\text { operador }\end{array}$ & 0,18 & 0,52 \\
\hline $\begin{array}{c}\text { Precisión } \\
\text { multilaboratorio }\end{array}$ & 0,29 & 0,81 \\
\hline
\end{tabular}

\subsection{Métodos de ensayo para determinar el conte- nido de asfalto de mezclas asfálticas en caliente (MAC) mediante el método de ignición (INTE 04- 01-09-06)}

Este método de ensayo tiene como objetivo determinar el contenido de asfalto de mezclas asfálticas en caliente (MAC) por ignición a temperaturas que alcanzan el punto de inflamación del ligante asfáltico en un horno. El equipo más relevante para esta prueba es: horno de ignición, canastas, bandeja tipo charola, horno, balanza, equipo de seguridad y equipo misceláneo. Se ensayan mínimo 2 especímenes por muestra.

Método A (balanza interna): Para realizar este ensayo se debe inicialmente precalentar el horno de ignición a (540 $\pm 5){ }^{\circ} \mathrm{C}$ y secar el espécimen hasta masa constante a una temperatura de $(105 \pm 5){ }^{\circ} \mathrm{C}$. Una vez pesadas la canasta y la bandeja se debe de distribuir uniformemente el espécimen de ensayo en las mismas y someterlos a pesaje para calcular la masa inicial del espécimen. Luego se ingresa la masa inicial del espécimen en gramos en el controlador del horno de ignición, y se debe verificar que sea la misma que la registrada dentro de $\pm 5 \mathrm{~g}$, seguidamente inicia el proceso de combustión y cuando el cambio en la masa no excede de 0,01\% para 3 min consecutivos el proceso de combustión se detiene.

El resultado obtenido del equipo se tiene que corregir por el factor de corrección porque ciertas fracciones de agregado se desintegran a la temperatura de combustión y por el contenido de agua en la mezcla cuando sea producida en planta.

Método B (sin balanza): Este método se diferencia del anterior en que luego de pesar las canastas y bandejas se debe de incinerar el espécimen de ensayo en el horno al menos 45 min y luego dejar que se enfrié por 30 min y registrar la masa. Se repite lo anterior con tiempos de 15 minutos en el horno y media hora de enfriamiento hasta que el cambio en la masa medida inicial (WA) o exceda en 0,01 \% la masa inicial del ensayo $\left(W_{S}\right)$.

$$
A C \%=\left(\frac{W_{s}-W_{A}}{W_{s}} * 100\right)-C_{F}
$$


Los criterios de aceptación del Método A son los siguientes

\begin{tabular}{|c|c|c|}
\hline \multicolumn{2}{|c|}{ Tabla 7. Criterios de aceptación INTE-04-01-09-06 } \\
\hline $\begin{array}{c}\text { Índice de ensayo } \\
\text { y tipo }\end{array}$ & $\begin{array}{c}\text { Desviación } \\
\text { estándar (\%) }\end{array}$ & $\begin{array}{c}\text { Rango aceptable de } \\
\text { dos resultados (\%) }\end{array}$ \\
\hline $\begin{array}{c}\text { Precisión de un } \\
\text { operador }\end{array}$ & 0,04 & 0,11 \\
\hline $\begin{array}{c}\text { Precisión } \\
\text { multilaboratorio }\end{array}$ & 0,06 & 0,17 \\
\hline
\end{tabular}

\subsection{Métododeensayoparaprepararespecímenes de mezcla asfáltica usando el quipo Marshall (INTE 04-01-10-06)}

Este método de ensayo tiene como objetivo definir la preparación y compactación de especímenes cilíndricos de mezclas asfálticas para pavimentos, con un diámetro de $102 \mathrm{~mm}$ y una altura nominal de $64 \mathrm{~mm}$ utilizando el método Marshall original y las subsecuentes variaciones. El equipo más relevante para esta prueba es: ensamble del molde para especímenes, extractor de especímenes, martillos de compactación, pedestal de compactación, sistema de sujetación de molde, hornos o planillas de calor y aparato mezclador.

Se deben de preparar como mínimo 3 especímenes. Inicialmente se debe de secar los agregados hasta masa constante y tamizarlos una vez fríos. Se debe de pesar en bandejas separadas las cantidades requeridas de cada fracción de tamaño para producir una mezcla y calentarlos a la temperatura de mezclado más $28^{\circ} \mathrm{C}$, seguidamente se mezcla en seco con una cuchara o espátula formando un cráter dentro del agregado y verter la masa requerida de material asfáltico. Determinar el peso total antes de proceder al mezclado, el cual se debe de hacer rápido en $60 \mathrm{~s}$ para un único espécimen y aproximadamente $120 \mathrm{~s}$ para especímenes múltiples. Se debe acondicionar los especímenes individualmente en contenedores de metal tapados en un horno a temperatura de $8{ }^{\circ} \mathrm{C}$ a $11{ }^{\circ} \mathrm{C}$ sobre la temperatura de compactación por mínimo $1 \mathrm{~h}$ y máximo $2 \mathrm{~h}$. A la hora de la compactación se debe: colocar el papel no absorbente dentro del molde, colocar la mezcla dentro del mismo introducir una espátula vigorosamente 15 veces alrededor del perímetro y 10 veces sobre el interior para finalmente colocar otra pieza de papel no absorbente en la parte superior. El ensamble del molde se debe colocar en el pedestal de compactación y con el sistema de sujetación sostener el molde y aplicar el número de golpes específicos con el martillo de compactación. Aplicar el mismo número de golpes de compactación en la cara contraria del espécimen y retirar el plato base y collarín. Permitir que el espécimen se enfrié a temperatura ambiente.

\subsection{Método de ensayo para estabilidad y flujo Marshall de mezclas asfálticas (INTE 04-01-11-06)}

Este método de ensayo tiene como objetivo determinar la resistencia al flujo plástico de especímenes cilíndricos de mezclas asfálticas para pavimentos, con un diámetro de 102 $\mathrm{mm}$, aplicando la carga en dirección perpendicular al eje del cilindro utilizando el equipo Marshall. El equipo más relevante para esta prueba es: muela de carga, maquina de carga a compresión, dispositivo para medir carga, medidor de flujo, baño de agua, horno, baño de aire y termómetro.

Para la realización de este ensayo se debe de tener como mínimo tres especímenes de una mezcla dada los cuales se tienen que enfriar a temperatura ambiente luego de la compactación. Seguidamente se someten a un baño de agua durante $30 \mathrm{~min}$ a $40 \mathrm{~min}$, o en un horno por $120 \mathrm{~min}$ a 130 min o en una cámara ambientadora por $120 \mathrm{~min}$ a $130 \mathrm{~min}$ a una temperatura de $(60 \pm 1){ }^{\circ} \mathrm{C}$, para cemento asfáltico. Seguidamente se colocan los especímenes en el segmento inferior de la muela y el ensamble completo en posición sobre la máquina de carga manteniendo la manga guía del flujo firmemente sobe el segmento superior de la muela de falla, mientras la carga está siendo aplicada. Se debe aplicar la carga al espécimen por medio de un movimiento de velocidad constante de carga de $(50 \pm 5) \mathrm{mm} / \mathrm{min}$, hay dos métodos de medición: Método A donde se utiliza un marco de carga con un anillo de carga y un deformímetro graduado o medidor de flujo (Método Tradicional), o Método B que se utiliza un graficador de carga-deformación en conjunto con una celda de carga y un transductor diferencial de variable lineal (LVDT) u otro dispositivo automático de adquisición de datos (Método Automático). El flujo corresponde al punto sobre la curva que está a seis puntos de flujo (o 1,5 mm) hacia la derecha de la línea tangente. La estabilidad Marshall está definida como la carga correspondiente al flujo. 

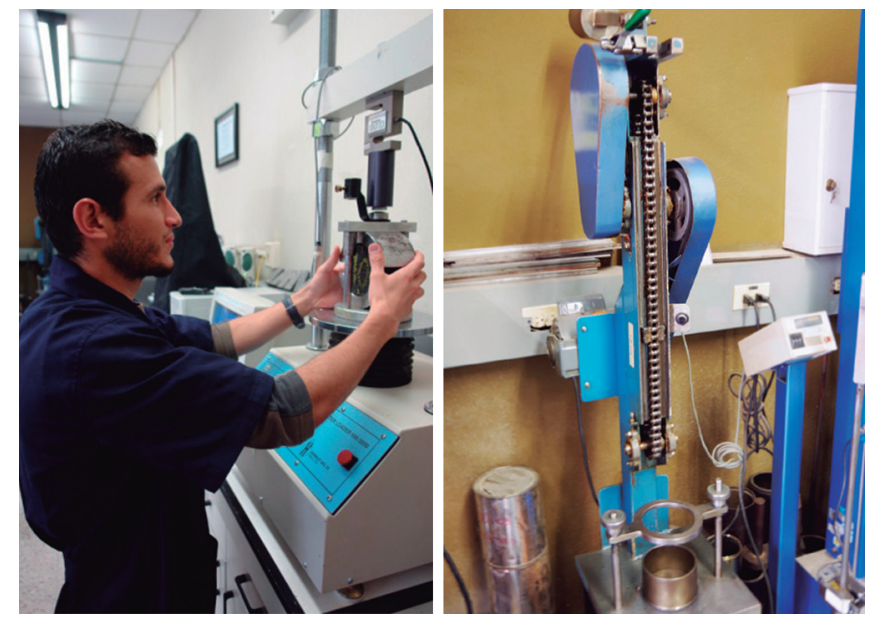

Figura 5. Colocación de Muestra para la Aplicación de Carga y Equipo de Compactación Marshall . Fuente: LanammeUCR, 2016.

Los criterios de aceptación del método de Estabilidad Marshall son los siguientes:

\begin{tabular}{|c|c|c|}
\hline \multicolumn{2}{|c|}{ Tabla 8. Criterios de aceptación INTE-04-01-11-06 } \\
\hline $\begin{array}{c}\text { Índice de ensayo } \\
\text { y tipo }\end{array}$ & $\begin{array}{c}\text { Desviación } \\
\text { estándar (\%) }\end{array}$ & $\begin{array}{c}\text { Rango aceptable de } \\
\text { dos resultados (\%) }\end{array}$ \\
\hline $\begin{array}{c}\text { Precisión de un } \\
\text { operador }\end{array}$ & 6 & 16 \\
\hline $\begin{array}{c}\text { Precisión } \\
\text { multilaboratorio }\end{array}$ & 16 & 43 \\
\hline
\end{tabular}

Los criterios de aceptación método del Flujo Marshall son los siguientes:

\begin{tabular}{|c|c|c|}
\hline \multicolumn{2}{|c|}{ Tabla 9. Criterios de aceptación INTE-04-01-11-06 } \\
\hline $\begin{array}{c}\text { Índice de ensayo } \\
\text { y tipo }\end{array}$ & $\begin{array}{c}\text { Desviación } \\
\text { estándar (\%) }\end{array}$ & $\begin{array}{c}\text { Rango aceptable de } \\
\text { dos resultados (\%) }\end{array}$ \\
\hline $\begin{array}{c}\text { Precisión de un } \\
\text { operador }\end{array}$ & 9 & 26 \\
\hline $\begin{array}{c}\text { Precisión } \\
\text { multilaboratorio }\end{array}$ & 20 & 58 \\
\hline
\end{tabular}

\subsection{Método de ensayo para el muestreo de mez- clas asfálticas para pavimentos (INTE 04-01-12-06)}

Este método de ensayo cubre el muestreo de mezclas asfálticas en los puntos de producción, almacenamiento, suministro y sitio.

Inspección: el material debe de ser inspeccionado para determinar variaciones discernibles.

\section{Muestreo:}

- Muestreo en la banda transportadora: Se debe detener la banda transportadora y seleccionar aleatoriamente al menos tres áreas de aproximadamente el mismo tamaño para conformar la muestra.

- Muestreo en los camiones de transporte: Por un método aleatorio, se debe seleccionar las unidades de la producción que serán muestreadas. Se debe de obtener al menos 3 muestras evitando muestrear en la parte superficial.

- Muestreo en la carretera antes de la compactación: Se debe obtener de la unidad que este siendo muestreada al menos 3 incrementos aproximadamente iguales y combinarlas para formar una única muestra.

- Muestreo de una banda transportadora discontinua que lleva mezcla a depósitos al silo de almacenamiento: se debe realizar de manera aleatoria basado en la capacidad del silo; deteniendo la banda inmediatamente después de que tambor mezclador descargue y cavar un hoyo de $150 \mathrm{~mm}$ y obtener 3 incrementos.

- Muestreo en una tolva que alimenta una caja transportadora que entrega la mezcla al silo de almacenamiento: Se debe obtener 3 incrementos aleatorios pasando un balde o bandeja a través del flujo completo de materiales que caen desde la tolva hasta la banda transportadora

- Muestreo en la carretera después de la compactación: Se debe obtener 3 incrementos aleatorios de la carretera para el espesor completo de la capa del material colocado, con el cuidado de no incluir material de capas inferiores.

- Muestreo en apilamientos de mezclas asfálticas en frío: Se debe remover la capa rígida sobre la superficie del apilamiento una profundidad de $100 \mathrm{~mm}$ en un área de $1 \mathrm{~m} 2$ y tomar 3 incrementos de cantidades aproximadamente iguales.

Número y tamaño de las muestras de campo: el número de muestra de campo requeridas depende de lo críticas que sean las propiedades a ser medidas y de la variabilidad de las mismas. Esta norma contiene una tabla con todas las especificaciones de área y peso adecuado para cada tamaño nominal de agregado. 
Transporte de las muestras: Se debe de hacer en recipientes que impidan la pérdida o contaminación de cualquier parte de la muestra o daño del interior del mismo. Estos deben de venir identificados individualmente con la información requerida

\subsection{Método de ensayo para el análisis granulo- métrico del agregado extraído (INTE 04-01-13-09)}

Este método de ensayo tiene como objetivo determinar la distribución de tamaños de partícula de agregados finos y gruesos extraídos de mezclas asfálticas en caliente (MAC). El equipo más relevante para esta prueba es: balanza, tamices, tamizador mecánico y horno. Para la realización de este ensayo se debe registrar la masa de la mezcla y luego de ser colocada en un contenedor, recubrirla con agua y agente tensoactivo. Seguidamente agitar y verter el contenido en una malla $\mathrm{N}^{\circ}$ 10 o $\mathrm{N}^{\circ} 16$ seguida por un tamiz $\mathrm{N}^{\circ} 200$; repetir hasta que el agua salga clara. Todo el contenido debe de ser regresado a la muestra y debidamente secado a masa constante. Colocar los tamices en orden descendiente, incluyendo el tamiz $\mathrm{N}^{\circ} 200$, y colocar la muestra en el tamiz superior para ser agitado mecánicamente. Continúe el tamizado por un tiempo suficiente y de tal forma que después de finalizar, no más de un $0,5 \%$ por masa del total de la muestra pase cualquier tamiz durante $60 \mathrm{~s}$ de tamizado manual. Finalmente determinar la masa del material retenido en cada malla con la balanza, incluyendo el pasando por el $\mathrm{N}^{\circ} 200$.

Los criterios de aceptación de la prueba son los siguientes:

\begin{tabular}{|c|c|c|c|c|}
\hline & \multicolumn{2}{|c|}{$\begin{array}{c}\text { Porcentaje total de } \\
\text { Material Pasando } \\
\text { un Tamiz }\end{array}$} & $\begin{array}{l}\text { Desviación } \\
\text { Estándar } \\
(\%)\end{array}$ & $\begin{array}{c}\text { Rango } \\
\text { Aceptable para } \\
\text { Dos Resultados } \\
(\%)\end{array}$ \\
\hline \multirow{7}{*}{$\begin{array}{l}\text { Precisión de } \\
\text { un operador }\end{array}$} & $<100$ & $\geq 95$ & 0,49 & 1,4 \\
\hline & $<95$ & $\geq 40$ & 1,06 & 3,0 \\
\hline & $<40$ & $\geq 25$ & 0,65 & 1,8 \\
\hline & $<25$ & $\geq 10$ & 0,46 & 1,3 \\
\hline & $<10$ & $\geq 5$ & 0,29 & 0,8 \\
\hline & $<5$ & $\geq 2$ & 0,21 & 0,6 \\
\hline & $<2$ & $\geq 0$ & 0,17 & 0,5 \\
\hline
\end{tabular}

\begin{tabular}{|c|c|c|c|c|}
\hline \multicolumn{5}{|c|}{ Tabla 10. Criterios de aceptación INTE-04-01-13-09 } \\
\hline & \multicolumn{2}{|c|}{$\begin{array}{l}\text { Porcentaje total de } \\
\text { Material Pasando } \\
\text { un Tamiz }\end{array}$} & $\begin{array}{c}\text { Desviación } \\
\text { Estándar } \\
(\%)\end{array}$ & $\begin{array}{c}\text { Rango } \\
\text { Aceptable para } \\
\text { Dos Resultados } \\
(\%)\end{array}$ \\
\hline \multirow{7}{*}{$\begin{array}{l}\text { Precisión } \\
\text { Multi- } \\
\text { laboratorio }\end{array}$} & $<100$ & $\geq 95$ & 0,57 & 1,6 \\
\hline & $<95$ & $\geq 40$ & 1,24 & 3,5 \\
\hline & $<40$ & $\geq 25$ & 0,84 & 2,4 \\
\hline & $<25$ & $\geq 10$ & 0,81 & 2,3 \\
\hline & $<10$ & $\geq 5$ & 0,56 & 1,6 \\
\hline & $<5$ & $\geq 2$ & 0,43 & 1,2 \\
\hline & $<2$ & $\geq 0$ & 0,32 & 0,9 \\
\hline
\end{tabular}

\section{COMPARACIÓN CON LAS NORMAS AASHTO Y ASTM ACTUALES}

A continuación se presenta en forma de tablas las diferencias más importantes que hay entre las normas INTECO y AASHTO/ASTM.

\begin{tabular}{|} 
Tabla 11. Tabla Comparativa del Equipo Utilizado en las \\
Normas INTECO con el Utilizado en las Normas \\
ASTM y AASHTO \\
\hline \multicolumn{1}{|c|}{ Equipo } & \multicolumn{1}{|c|}{ ASTM } & AASHTO \\
\hline INTE (04-01-01-04) & $\begin{array}{l}\text { ASTM no especifica } \\
\text { accesorios de sus- } \\
\text { pensión. La balanza } \\
\text { debe de ser de 3 ci- } \\
\text { fras significativas y no } \\
\text { de resolución a 0,1 \% }\end{array}$ & \\
AASHTO (T 166-11) & El mismo \\
\hline IINTE (04-01-02-04) & $\begin{array}{l}\text { No contiene acceso- } \\
\text { rio de suspensión, ni } \\
\text { ASTM (D1188-07) }\end{array}$ & \\
AASHTO (T 331-10) & recipiente aforado. & \\
\hline
\end{tabular}




\begin{tabular}{|c|c|c|}
\hline \multicolumn{3}{|c|}{$\begin{array}{l}\text { Tabla 11. Tabla Comparativa del Equipo Utilizado er } \\
\text { Normas INTECO con el Utilizado en las Normas } \\
\text { ASTM y AASHTO }\end{array}$} \\
\hline Equipo & ASTM & AASHTO \\
\hline $\begin{array}{l}\text { INTE (04-01-03-05) } \\
\text { ASTM (D2041M-11) } \\
\text { AASHTO ( T 209-11) }\end{array}$ & $\begin{array}{l}\text { INTECO no incluye } \\
\text { agitadores mecáni- } \\
\text { cos ni matraz. } \\
\text { ASTM se da una espe- } \\
\text { cificación detallada } \\
\text { de los tipos de conte- } \\
\text { nedores. }\end{array}$ & $\begin{array}{l}\text { INTECO no incluye } \\
\text { agitadores mecá- } \\
\text { nicos }\end{array}$ \\
\hline $\begin{array}{l}\text { INTE (04-01-04-05) } \\
\text { ASTM (D3203M-11) } \\
\text { AASHTO (T 269-14) }\end{array}$ & NA & NA \\
\hline $\begin{array}{l}\text { INTE (04-01-05-05) } \\
\text { ASTM ( D 4867M-14) } \\
\text { AASHTO ( T283-14) }\end{array}$ & $\begin{array}{l}\text { Utiliza manómetro y } \\
\text { un anillo de dinamó- } \\
\text { metro. } \\
\text { No utiliza bandejas ni } \\
\text { bolsas plásticas como } \\
\text { en el caso de INTECO }\end{array}$ & $\begin{array}{l}\text { Incluye equipo para } \\
\text { calcular la máxima } \\
\text { gravedad específica. } \\
\text { Contiene un congela- } \\
\text { dor a }(-18 \pm 3)^{\circ} \mathrm{C} \text {. } \\
\text { Contiene un cilindro } \\
\text { graduado de } 10 \mathrm{ml}\end{array}$ \\
\hline $\begin{array}{l}\text { INTE (04-01-06-05) } \\
\text { ASTM (D1074-02) } \\
\text { AASHTO (T 167-10) }\end{array}$ & $\begin{array}{l}\text { INTECO no incluye } \\
\text { el baño de aire para } \\
\text { mantener el espéci- } \\
\text { men a }(25 \pm 0,5)^{\circ} \mathrm{C}\end{array}$ & $\begin{array}{l}\text { Incluye también el } \\
\text { baño de aire que no } \\
\text { se utiliza en el ensayo } \\
\text { de INTECO }\end{array}$ \\
\hline $\begin{array}{l}\text { INTE (04-01-07-05) } \\
\text { ASTM (D1075-11) } \\
\text { AASHTO (T 165-02) }\end{array}$ & $\begin{array}{l}\text { Se especifica que el } \\
\text { baño de agua y una } \\
\text { balanza tiene que es- } \\
\text { tar equipado con un } \\
\text { accesorio de pesaje } \\
\text { INTECO no incluye } \\
\text { termómetros ni ba- } \\
\text { ños de aire. }\end{array}$ & $\begin{array}{l}\text { Esta norma fue } \\
\text { remplazada por la de } \\
\text { ASTM D1075 }\end{array}$ \\
\hline $\begin{array}{l}\text { INTE (04-01-08-05) } \\
\text { ASTM (D2172M-11) } \\
\text { AASHTO (T164-14) }\end{array}$ & El mismo & El mismo \\
\hline $\begin{array}{l}\text { INTE (04-01-09-06) } \\
\text { ASTM ( D6307-16) } \\
\text { AASHTO (T 308-10) }\end{array}$ & $\begin{array}{l}\text { No se especifica el } \\
\text { horno de ignición }\end{array}$ & El mismo \\
\hline
\end{tabular}

\begin{tabular}{|c|c|c|}
\hline \multicolumn{3}{|c|}{$\begin{array}{l}\text { Tabla 11. Tabla Comparativa del Equipo Utilizado en las } \\
\text { Normas INTECO con el Utilizado en las Normas } \\
\text { ASTM y AASHTO }\end{array}$} \\
\hline Equipo & ASTM & AASHTO \\
\hline $\begin{array}{l}\text { INTE (04-01-10-06) } \\
\text { ASTM (D6926-04) }\end{array}$ & El mismo & NA \\
\hline $\begin{array}{l}\text { INTE (04-01-11-06) } \\
\text { ASTM (D979-01) } \\
\text { AASHTO (T 245-15) }\end{array}$ & El mismo & $\begin{array}{l}\text { Las normas AASHTO } \\
\text { hacen una inclusión } \\
\text { mucho más especí- } \\
\text { fica para el manejo } \\
\text { de especímenes que } \\
\text { INTECO incluyen en } \\
\text { su descripción: mol- } \\
\text { de de especímenes, } \\
\text { extractor de especí- } \\
\text { menes, martillo com- } \\
\text { pactador, pedestales } \\
\text { compactados, base } \\
\text { para especímenes, } \\
\text { dinamómetro de aro, } \\
\text { contenedores, balan- } \\
\text { zas, guantes y marca- } \\
\text { dores }\end{array}$ \\
\hline $\begin{array}{l}\text { INTE (04-01-12-05) } \\
\text { ASTM (D979-01) } \\
\text { AASHTO (T 168-11) }\end{array}$ & NA & NA \\
\hline $\begin{array}{l}\text { INTE (04-01-13-09) } \\
\text { ASTM (D5444-15) } \\
\text { AASHTO (T 308-10) }\end{array}$ & El mismo & $\begin{array}{l}\text { Cuando el mecanis- } \\
\text { mo de lavado mecá- } \\
\text { nico es utilizado el } \\
\text { proceso de introduc- } \\
\text { ción de agua, agita- } \\
\text { ción y decantación } \\
\text { debe de ser continuo }\end{array}$ \\
\hline
\end{tabular}

\begin{tabular}{|c|c|c|}
\hline $\begin{array}{l}\text { Tabla 12. Tabla } \\
\text { en las Normas }\end{array}$ & $\begin{array}{l}\text { mparativa del Proc } \\
\text { TECO con los Segui } \\
\text { ASTM y AASHTO }\end{array}$ & $\begin{array}{l}\text { dimiento Seguido } \\
\text { os en las Normas }\end{array}$ \\
\hline Procedimiento & ASTM & AASHTO \\
\hline $\begin{array}{l}\text { INTE (04-01-01-04) } \\
\text { ASTM (D2726M-13) } \\
\text { AASHTO ( T 166-11) }\end{array}$ & $\begin{array}{l}\text { El peso seco se regis- } \\
\text { tra al final del ensayo } \\
\text { No contiene el Méto- } \\
\text { do B ni el Método C }\end{array}$ & $\begin{array}{l}\text { El peso seco se regis- } \\
\text { tra al final del ensayo } \\
\text { No contiene el Méto- } \\
\text { do B ni el Método C }\end{array}$ \\
\hline
\end{tabular}


Tabla 12. Tabla Comparativa del Procedimiento Seguido

en las Normas INTECO con los Seguidos en las Normas

\section{ASTM y AASHTO}

\section{Procedimiento}

ASTM

AASHTO

\begin{tabular}{|c|c|c|}
\hline $\begin{array}{l}\text { INTE (04-01-02-04) } \\
\text { ASTM (D1188-07) } \\
\text { AASHTO (T 331-10) }\end{array}$ & $\begin{array}{l}\text { No contiene el Méto- } \\
\text { do } B \text {, únicamente se } \\
\text { realiza el de pesado } \\
\text { en aire }\end{array}$ & NA \\
\hline $\begin{array}{l}\text { INTE (04-01-03-05) } \\
\text { ASTM (D2041M-11) } \\
\text { AASHTO ( T 209-11) }\end{array}$ & $\begin{array}{l}\text { No incluye la sepa- } \\
\text { ración de partículas } \\
\text { inicial sino posterior } \\
\text { al secado. } \\
\text { No contiene el méto- } \\
\text { do de determinación } \\
\text { por matraz }\end{array}$ & $\begin{array}{l}\text { El procedimiento ini- } \\
\text { cia al remover el aire } \\
\text { en la muestra. } \\
\text { Existe una separa- } \\
\text { ción de métodos de } \\
\text { agitación. }\end{array}$ \\
\hline $\begin{array}{l}\text { INTE (04-01-04-05) } \\
\text { ASTM (D3203M-11) } \\
\text { AASHTO (T 269-14) }\end{array}$ & $\begin{array}{l}\text { No presenta dife- } \\
\text { rencias significativas } \\
\text { para este ensayo }\end{array}$ & El mismo \\
\hline $\begin{array}{l}\text { INTE (04-01-05-05) } \\
\text { ASTM ( D 4867M-14) } \\
\text { AASHTO ( T283-14) }\end{array}$ & $\begin{array}{l}\text { Parcialmente se satu- } \\
\text { ra la muestra en agua } \\
\text { destilada y se le aña- } \\
\text { de presión de } 70 \mathrm{kPa} \\
\text { Se calcula el hincha- } \\
\text { miento. } \\
\text { INTECO especifica un } \\
\text { daño en escala de } 0-5\end{array}$ & $\begin{array}{l}\text { El congelador se } \\
\text { utiliza en la prepara- } \\
\text { ción del espécimen } \\
\text { el cual se debe de } \\
\text { dejar durante } 16 \text { ho- } \\
\text { ras como mínimo en } \\
\text { bolsas plásticas an- } \\
\text { tes de ser ensayado. }\end{array}$ \\
\hline $\begin{array}{l}\text { INTE (04-01-06-05) } \\
\text { ASTM (D1074-02) } \\
\text { AASHTO (T 167-10) }\end{array}$ & $\begin{array}{l}\text { Al llevar los especí- } \\
\text { menes de ensayo a la } \\
\text { temperatura de ensa- } \\
\text { yo INTECO recomien- } \\
\text { da el uso de cámara } \\
\text { térmica un cuarto con } \\
\text { temperatura contro- } \\
\text { lada o baño de agua. } \\
\text { ASTM utiliza baño de } \\
\text { aire }\end{array}$ & $\begin{array}{l}\text { Al llevar los especí- } \\
\text { menes de ensayo a la } \\
\text { temperatura de ensa- } \\
\text { yo INTECO recomien- } \\
\text { da el uso de cámara } \\
\text { térmica un cuarto con } \\
\text { temperatura contro- } \\
\text { lada o baño de agua. } \\
\text { AASHTO utiliza baño } \\
\text { de aire. }\end{array}$ \\
\hline $\begin{array}{l}\text { INTE (04-01-07-05) } \\
\text { ASTM (D1075-11) } \\
\text { AASHTO (T 165-02) }\end{array}$ & $\begin{array}{l}\text { Se especifica que } \\
\text { deben de ser } 2 \text { gru- } \\
\text { pos con } 3 \text { muestras } \\
\text { cada uno mientras } \\
\text { que en INTECO solo } \\
\text { dicen que debe de } \\
\text { ser } 2 \text { grupos con un } \\
\text { mismo número de } \\
\text { muestras }\end{array}$ & $\begin{array}{l}\text { Esta norma fue rem- } \\
\text { plazada por la de } \\
\text { ASTM D1075 }\end{array}$ \\
\hline
\end{tabular}

\begin{tabular}{|c|c|c|}
\hline \multicolumn{3}{|c|}{$\begin{array}{l}\text { Tabla 12. Tabla Comparativa del Procedimiento Seguido } \\
\text { en las Normas INTECO con los Seguidos en las Normas } \\
\text { ASTM y AASHTO }\end{array}$} \\
\hline Procedimiento & ASTM & AASHTO \\
\hline $\begin{array}{l}\text { INTE (04-01-08-05) } \\
\text { ASTM (D2172M-11) } \\
\text { AASHTO (T164-14) }\end{array}$ & El mismo & El mismo \\
\hline $\begin{array}{l}\text { INTE (04-01-09-06) } \\
\text { ASTM ( D6307-16) } \\
\text { AASHTO (T 308-10) }\end{array}$ & $\begin{array}{l}\text { Se pesa de antemano } \\
\text { las charolas lo más } \\
\text { cercano a } 0,1 \mathrm{~g} \text {. } \\
\text { Se deja enfriar duran- } \\
\text { te } 10 \text { minutos la mez- } \\
\text { cla antes de antes de } \\
\text { la ignición. }\end{array}$ & $\begin{array}{l}\text { El horno se preca- } \\
\text { lienta a } 538^{\circ} \mathrm{C} \text { para } \\
\text { ambos métodos. }\end{array}$ \\
\hline $\begin{array}{l}\text { INTE (04-01-10-06) } \\
\text { ASTM (D6926-04) }\end{array}$ & El mismo & NA \\
\hline $\begin{array}{l}\text { INTE (04-01-11-06) } \\
\text { ASTM (D979-01) } \\
\text { AASHTO (T 245-15) }\end{array}$ & El mismo & $\begin{array}{l}\text { Este procedimiento } \\
\text { agrega un rango de } \\
\text { temperaturas al cual } \\
\text { mantener la cabeza } \\
\text { de prueba }\end{array}$ \\
\hline $\begin{array}{l}\text { INTE (04-01-12-05) } \\
\text { ASTM (D979-01) } \\
\text { AASHTO (T 168-11) }\end{array}$ & $\begin{array}{l}\text { Siguen el mismo pro- } \\
\text { cedimiento basándo- } \\
\text { se en prácticas de las } \\
\text { normas ASTM }\end{array}$ & $\begin{array}{l}\text { La norma AASHTO } \\
\text { agrega procedimien- } \\
\text { to al muestreo en } \\
\text { carretera antes de } \\
\text { la compactación en } \\
\text { caso de que la mezcla } \\
\text { este fría. Además, si } \\
\text { ha sido aplicada en } \\
\text { una capa uniforme } \\
\text { las muestras no se to- } \\
\text { marán en intervalos } \\
\text { de más de } 150 \mathrm{~m} \text {. }\end{array}$ \\
\hline $\begin{array}{l}\text { INTE (04-01-13-09) } \\
\text { ASTM (D5444-15) } \\
\text { AASHTO (T 308-10) }\end{array}$ & El mismo & $\begin{array}{l}\text { Cuando el mecanis- } \\
\text { mo de lavado mecá- } \\
\text { nico es utilizado el } \\
\text { proceso de introduc- } \\
\text { ción de agua, agita- } \\
\text { ción y decantación } \\
\text { debe de ser continuo }\end{array}$ \\
\hline
\end{tabular}


Tabla 13. Tabla Comparativa de los Criterios de

Aceptación Utilizado en las Normas INTECO con los

Utilizados en las Normas ASTM y AASHTO

\begin{tabular}{|c|c|c|}
\hline $\begin{array}{l}\text { Criterios de } \\
\text { aceptación }\end{array}$ & ASTM & AASHTO \\
\hline $\begin{array}{l}\text { INTE (04-01-01-04) } \\
\text { ASTM (D2726M-13) } \\
\text { AASHTO ( T 166-11) }\end{array}$ & $\begin{array}{l}\text { Se realiza una dife- } \\
\text { renciación en tama- } \\
\text { ños máximos } \\
\text { nominales. Existe una } \\
\text { diferencia de alrede- } \\
\text { dor de un } 5 \% \text { para } \\
\text { un solo operador y } \\
\text { del } 80 \% \text { para multila- } \\
\text { boratorio. }\end{array}$ & $\begin{array}{l}\text { Existe una diferencia } \\
\text { de más del } 100 \% \\
\text { tanto para un solo } \\
\text { operador como para } \\
\text { multilaboratorio. }\end{array}$ \\
\hline $\begin{array}{l}\text { INTE (04-01-02-04) } \\
\text { ASTM (D1188-07) } \\
\text { AASHTO (T 331-10) }\end{array}$ & $\begin{array}{l}\text { INTE solo considera } \\
\text { por duplicado con el } \\
\text { mismo operador el } \\
\text { cual difiere del ASTM } \\
\text { en } 0,059\end{array}$ & NA \\
\hline $\begin{array}{l}\text { INTE (04-01-03-05) } \\
\text { ASTM (D2041M-11) } \\
\text { AASHTO ( T 209-11) }\end{array}$ & $\begin{array}{l}\text { Para el método } A \text {, di- } \\
\text { fieren en más de un } \\
100 \% \text {. } \\
\text { Para el método } B \text {, es } \\
\text { el mismo }\end{array}$ & $\begin{array}{l}\text { Para el método A } \\
\text { existe una diferencia } \\
\text { de aproximadamen- } \\
\text { te } 22 \% \text { en desviación } \\
\text { estándar y } 42 \% \text { en } \\
\text { rango aceptable de } \\
\text { dos resultados. Para } \\
\text { el método B en mul- } \\
\text { tilaboratorio presen- } \\
\text { ta una diferencia del } \\
\text { alrededor de un } 90 \% \\
\text { en desviación están- } \\
\text { dar y rango acepta- } \\
\text { ble de dos resultados }\end{array}$ \\
\hline $\begin{array}{l}\text { INTE (04-01-04-05) } \\
\text { ASTM (D3203M-11) } \\
\text { AASHTO (T 269-14) }\end{array}$ & $\begin{array}{l}\text { Los criterios de acep- } \\
\text { tación están sujetos a } \\
\text { los ensayos de grave- } \\
\text { dades específicas }\end{array}$ & $\begin{array}{l}\text { La desviación están- } \\
\text { dar para el método } \\
\text { A varían en un } 34 \% \\
\text { para un solo opera- } \\
\text { dor y para el Método } \\
\text { B la variación es de } \\
\text { más de un } 90 \% \text { para } \\
\text { un solo operador y } \\
\text { más de un } 100 \% \text { para } \\
\text { multilaboratorio. }\end{array}$ \\
\hline
\end{tabular}

Tabla 13. Tabla Comparativa de los Criterios de

Aceptación Utilizado en las Normas INTECO con los

Utilizados en las Normas ASTM y AASHTO

\begin{tabular}{|c|c|c|}
\hline $\begin{array}{l}\text { Criterios de } \\
\text { aceptación }\end{array}$ & ASTM & AASHTO \\
\hline $\begin{array}{l}\text { INTE (04-01-05-05) } \\
\text { ASTM ( D 4867M-14) } \\
\text { AASHTO ( T283-14) }\end{array}$ & $\begin{array}{l}\text { ASTM si incluye cri- } \\
\text { terios de aceptación. } \\
\text { Para un único ope- } \\
\text { rador la desviación } \\
\text { estándar es de } 55 \mathrm{kPa} \\
\text { y la diferencia entre } \\
\text { duplicados de espé- } \\
\text { cimen es de } 159 \mathrm{kPa} \text {. } \\
\text { Para multilaboratorio } \\
\text { es de } 8 \% \text { la desvia- } \\
\text { ción estándar y una } \\
\text { diferencia del } 23 \% \text {. }\end{array}$ & NA \\
\hline $\begin{array}{l}\text { INTE (04-01-06-05) } \\
\text { ASTM (D1074-02) } \\
\text { AASHTO (T 167-10) }\end{array}$ & $\begin{array}{l}\text { Ambos utilizan el } \\
\text { mismo criterio de } \\
\text { aceptación. }\end{array}$ & $\begin{array}{l}\text { Ambos utilizan el } \\
\text { mismo criterio de } \\
\text { aceptación. }\end{array}$ \\
\hline $\begin{array}{l}\text { INTE (04-01-07-05) } \\
\text { ASTM (D1075-11) } \\
\text { AASHTO (T 165-02) }\end{array}$ & El mismo & $\begin{array}{l}\text { Esta norma fue rem- } \\
\text { plazada por la de } \\
\text { ASTMD1075 }\end{array}$ \\
\hline $\begin{array}{l}\text { INTE (04-01-08-05) } \\
\text { ASTM (D2172M-11) } \\
\text { AASHTO (T164-14) }\end{array}$ & $\begin{array}{l}\text { ASTM divide los cri- } \\
\text { terios de aceptación } \\
\text { para el Método A, B, } \\
\text { C, D y E. } \\
\text { Para los primeros dos } \\
\text { métodos los criterios } \\
\text { difieren en más de un } \\
100 \%\end{array}$ & El mismo \\
\hline $\begin{array}{l}\text { INTE (04-01-09-06) } \\
\text { ASTM ( D6307-16) } \\
\text { AASHTO (T 308-10) }\end{array}$ & El mismo & $\begin{array}{l}\text { Los criterios difieren } \\
\text { en más de un } 100 \%\end{array}$ \\
\hline $\begin{array}{l}\text { INTE (04-01-10-06) } \\
\text { ASTM (D6926-04) }\end{array}$ & El mismo & NA \\
\hline
\end{tabular}


Tabla 13. Tabla Comparativa de los Criterios de

Aceptación Utilizado en las Normas INTECO con los

Utilizados en las Normas ASTM y AASHTO

\begin{tabular}{|c|c|c|}
\hline $\begin{array}{c}\text { Criterios de } \\
\text { aceptación }\end{array}$ & ASTM & AASHTO \\
\hline $\begin{array}{c}\text { INTE (04-01-11-06) } \\
\text { ASTM (D979-01) }\end{array}$ & El mismo & El mismo \\
AASHTO (T 245-15) & & \\
\hline INTE (04-01-12-05) & & \\
ASTM (D979-01) & & \\
AASHTO (T 168-11) & & \\
\hline INTE (04-01-13-09) & $\begin{array}{l}\text { Diferencia muy ligera. } \\
\text { Esta diferencia puede } \\
\text { ASTM (D5444-15) }\end{array}$ & $\begin{array}{l}\text { Diferencia muy ligera. } \\
\text { hacer que un mate- } \\
\text { hacer que un mate- } \\
\text { rial cumpla o no. }\end{array}$ \\
\hline rASHTO (T 308-10) & \begin{tabular}{l} 
rial cumpla o no \\
\hline
\end{tabular} \\
\hline
\end{tabular}

\section{CONCLUSIONES Y RECOMENDACIONES}

Hay diferencias importantes en todos los métodos de ensayo con respecto a las normas más actuales de ASTM y AASHTO sobre todo en los criterios de aceptación y rechazo. Esto es sumamente preocupante puesto que puede generar que en Costa Rica se estén aceptando resultados que internacionalmente se desechan por falta de precisión, lo que nos pone en desventaja a nivel mundial. Lo anterior sugiere que es sumamente urgente conformar un nuevo grupo de personas que estén dispuestas a actualizar dichos errores.

Específicamente, destacamos las siguientes conclusiones para los métodos:

Es importante que en el momento de llevar los especímenes a condición de superficie saturada seca no se exceda con el secado, puesto que esto puede generar que se extraigan partículas de agua resididas en los poros que no deberían de ser extraídas y pueden llegar a sesgar los resultados.

A pesar de que las normas estadounidense han desactualizado el método del recubrimiento de parafina para la determinación de la gravedad especifica se recomienda utilizarlo, y no sustituirlo por el de bolsas de vacíos puesto que este puede llegar a generar complicaciones a la hora de extraerles el vacio ya que se pueden llegar a perforar. Otra razón por la cual se prefiere el método de la parafina es porque es mucho más económico y da datos más exactos que el de bolsas al vacío ya que dicha parafina se introduce necesariamente en todos los poros del espécimen, algo que las bolsas no logran hacer con seguridad.

En las normas INTECO se presenta un método B para la determinación de la gravedad especifica máxima teórica y la densidad de mezclas, el cual se expone como opcional puesto que al ser normas basadas en las Estadounidenses (AASHTO, INTECO) no toman en consideración que en Costa Rica es esencial dicho proceso puesto que todos los agregados con los que se cuenta contienen más del $2 \%$ de absorción. Es decir, se considera un proceso de carácter obligatorio para este ensayo.

En el método para determinar la resistencia al daño incluido por la humedad en mezclas asfálticas compactadas, INTECO desecho la utilización de un congelador a la hora de condicionar la mezcla; esto no se realiza con el fin de similar condiciones climáticas (que en Costa Rica no existen) sino que más bien es una forma de acelerar el daño. Lo anterior puede generar que el método se vuelva robusto y que no permita diseñar una mezcla adecuada susceptible a la humedad.

Como se mencionó al inicio del artículo existió un Comité Técnico para "Mezclas Bituminosas" tanto para el inicio de la creación de las normas como para cuando se realizó la última en el 2009. Este trabajo fue un gran esfuerzo de los integrantes, que a pesar de ser un trabajo voluntario se pudo realizar, lo que demuestra que cuando hay conciencia de la importancia del trabajo se puede realizar tomando en cuenta todas las opiniones. A continuación presentamos dichos integrantes:

\begin{tabular}{|c|c|}
\hline \multicolumn{2}{|c|}{ Tabla 14. Integrantes del Comité Técnico 2004-200: } \\
\hline 2004 & 2009 \\
\hline Lanamme & Lanamme \\
\hline MOPT & MOPT ( laboratorios ) \\
\hline ACCCR & ITP \\
\hline CACISA & CACISA \\
\hline CONAVI & CONAVI \\
\hline Grupos Santa Fe & Castro y de la Torre \\
\hline \multirow[t]{4}{*}{ CONCORI } & LGC \\
\hline & OJM \\
\hline & Vieto y Asociados \\
\hline & TEC \\
\hline
\end{tabular}


Por medio de este artículo, que se espera haya sido suficientemente informativo, se invita a los anteriores miembros del comité técnico y a cualquier persona en el medio interesada a conformar un nuevo equipo de trabajo para lograr no sólo actualizar dichas normas sino que también crear nuevas, que regulen el estudio de las mezclas asfálticas en Costa Rica.

\section{REFERENCIAS}

- American Association of State Highway and Transportation Officials. (2011). Standard Specifications for Transportation Materials and Methods of Sampling and Testing (31st Edition) anda AASHTO Provisonal Standards. Washington, D.C: AASHTO.

American Society for Testing and Materials. (2015-2016). ANNUAL BOOK OF ASTM STANDARDS. Baltimore, MD, U.S.A: ASTM.

Humboldt. (2016). Construction Materials Testing Equipment. Disponible en: https://www.humboldtmfg.com/ [Accesado 22 Jun. 2017].

Instituto de Normas Técnicas de Costa Rica. (2004-2009). Metodos de Ensayo para Mezclas Asfálticas para Pavimentos. San Pedro, San José: INTECO. 